Birth date and sporting success

SIR - I have found a significant relationship between birth date and success in tennis and soccer. In the Netherlands and England, players born early in the competition year are more likely to participate in national soccer leagues. The high incidence of élite athletes born in the first quarter of the competition year can be

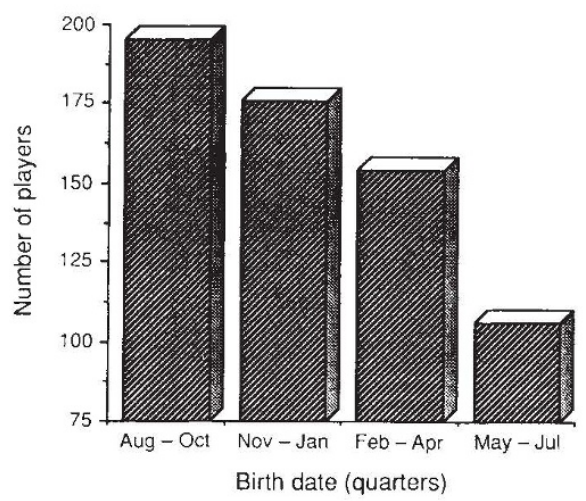

Relationship between birthdate and participation rates in Dutch soccer league. Note the ordinate begins at 75 players.

explained by the effects of age-group position.

In organized sport, talent is considered predominantly in terms of physical skills, and the influence of social and psychological factors is often ignored or underestimated'. Various studies have investigated the psychological characteristics of élite athletes ${ }^{2}$, but none has looked for an tribution is not uniform $(P<0.001)$ and a regression analysis demonstrates a clear linear relationship between month of birth and number of participants. The dates of birth of 621 players, compiled into quarters, are shown in the figure. This relationship cannot be attributed to the distribution of births in the Netherlands, as this is highly uniform.

We also inspected the distribution of the dates of birth of Engiish football players in league clubs in the period 1991-92 (ref. 3). Birth dates for all players were tabulated by month and compiled into quarters. The results (table) show the significant effect of date of birth on participation rate of soccer players within each of the national leagues, indicating that, as in the Netherlands, significantly more football players are born in the first quarter of the competition year (which starts in September in England).

There is a known relationship between date of birth and educational achievement ${ }^{4,5}$, implying that the younger children in any school year group are at a disadvantage compared to the older children. Children who participate in sports are also placed in age groups, and my results imply many athletes in organized sports may never get a fair chance because of this method of classification. Very little attention has been drawn to this problem. One of the few studies done in this area analysed the dates of birth of young Canadian hockey players in the 1983-84 season $^{6}$. Players possessing a relative age advantage (born in the months JanuaryJune) were more likely to participate in minor hockey and more likely to play for top teams than players in July-December.

More than 20 years ago, this journal

PARTICIPATION RATES INENGLISH SOCCER LEAGUES

\begin{tabular}{lccccccc}
\cline { 3 - 5 } League & \multicolumn{3}{c}{ Players in birthdate quarters } & \multicolumn{2}{c}{ Statistics } \\
& Sep-Nov & Dec-Feb & Mar-Apr & Jun-Aug & Total & $\chi^{2}$ & Sig. \\
FA premier & 288 & 190 & 147 & 136 & 761 & 75.53 & $P<0.0001$ \\
Division 1 & 264 & 169 & 154 & 147 & 734 & 48.47 & $P<0.0001$ \\
Division 2 & 251 & 168 & 123 & 131 & 673 & 61.11 & $P<0.0001$ \\
Division 3 & 217 & 169 & 121 & 102 & 609 & 52.38 & $P<0.0001$ \\
Total & 1,020 & 696 & 545 & 516 & 2.777 & 230.77 & $P<0.0001$
\end{tabular}

effect of age. I discovered a strikingly skewed distribution of the dates of birth of 12- to 16-year-old tennis players in the top rankings of the Dutch youth league. Half of a sample of 60 tennis players were born in the first 3 months of the year.

This discovery led me to consider the distribution of the dates of birth of professional soccer players. In the Netherlands, there are two leagues comprising a total of 36 clubs. I found a striking difference between participation rates of those born in August and July. The Dutch soccer competition year starts on the first of August. A $\chi^{2}$ test indicates that the dis- published an article concerning the relationship between season of birth and cognitive development ${ }^{7}$. The authors attributed this relationship to a fault in the British educational system. A similar rela-

1. Dudink. A. Eur. J. High Ability 1. 144. 150 (1990)

. Dudink. A \& Bakker. F. Ned. Tschr. Psychol 48 55-69 (1993)

3. Rollin. j. Rothmans Football Yearbook 1992-93 (Headline, London, 1992)

. Shearer, E. Educ. Res. 10.51-56 (1967).

5. Doornbos, K. Date of Birth and Scholastic Performance (Wolters-Noordhoff, Groningen, 1971)

6. Barnsley, R. H. \& Thompson, A. H. Can. J. Behav. Sci. 20 167-176 (1988).

Wiliams, Ph., Davies, P., Evans, R. \& Ferguson, N. Nature 228, 1033-1036 (1970) tionship was found ${ }^{5}$ in the Netherlands. Despite this, no action was undertaken to change the educational system. One can only hope that this will not be the case for sports.

\section{Ad Dudink}

Faculty of Psychology,

University of Amsterdam,

1018 WB Amsterdam, The Netherlands

\section{Sensory maps in the human brain}

SIR - Until a decade ago, it was widely believed that once neural pathways were laid down in fetal life or early infancy, little subsequent alteration of these pathways occurred in the adult human brain. Over the past decade, however, shifts of cortical sensory function in adult primates of 1-3 mm following deafferentation have been documented ${ }^{1}$. Pons et al. recently reported $^{2}$ that facial touch stimuli ipsilateral to a chronic upper limb deafferentation in adult macaques evoked responses of cells in the somatosensory S1 hand representation area with expansion of the facial cortical map by $10-14 \mathrm{~mm}$. V. S. R. et al. ${ }^{3-5}$ studied perception in human arm amputees and found that tactile stimuli applied to the lower facial region ipsilateral to the amputation evoked topographically organized, modalityspecific, referred sensations in the phantom limb. While such psychophysical findings in amputees and in neurological patients ${ }^{6}$ suggest a functional reorganization of the human somatosensory areas analogous to the physiological changes observed in macaques ${ }^{2}$, more direct evidence is needed.

For this purpose we developed a method of high-resolution, non-invasive somatosensory mapping, based on a magnetoencephalographic (MEG) approach already used and validated for presurgical mapping of brain somatosensory regions ${ }^{7}$. Our approach provides highly reproducible, detailed and accurate localizations of discrete areas of the face, hand and $\mathrm{arm}^{8}$.

A 37-channel Magnes biomagnetometer (Biomagnetic Technologies, Inc., San Diego) was used to record somatosensory responses evoked by painless tactile stimuli from two adult, human amputees (D.S. and F.A.) and four normal controls. Source localizations were calculated using a single equivalent current dipole (ECD) model ${ }^{7}$. D.S. was studied 8 years after traumatic avulsion of his left brachial plexus, and F.A. 11 years after accidental amputation of his right forearm $8 \mathrm{~cm}$ below the elbow. A detailed sensory homunculus was observed bilaterally in all four controls and on the unaffected hemisphere in both amputees. On the affected hemisphere, D.S. showed 